\title{
Coulisses
}

Revue de théâtre

14 | Printemps 1996

Varia

\section{A propos de Conversation chez les Stein sur Monsieur de Goethe absent}

\section{Liliane David}

\section{(2) OpenEdition}

1 Journals

Édition électronique

URL : http://journals.openedition.org/coulisses/4681

DOI : $10.4000 /$ coulisses.4681

ISSN : 2546-9460

Éditeur

Presses universitaires de Franche-Comté

\section{Édition imprimée}

Date de publication : 1 mai 1996

Pagination : 51

ISSN : 1150-594X

\section{Référence électronique}

Liliane David, "A propos de Conversation chez les Stein sur Monsieur de Goethe absent », Coulisses [En ligne], 14 | Printemps 1996, mis en ligne le 20 mars 2019, consulté le 27 octobre 2019. URL : http:// journals.openedition.org/coulisses/4681; DOI : 10.4000/coulisses.4681

Ce document a été généré automatiquement le 27 octobre 2019.

Coulisses 


\title{
A propos de Conversation chez les Stein sur Monsieur de Goethe absent
}

\author{
Liliane David
}

Liliane David a été l'interprète d'une pièce à un seul personnage, sorte de " discours d'une dame immobile sur ce qui aurait pu être sa vie ", mise en scène en 1991 par JeanLuc Lagarce. Elle évoque son travail avec le metteur en scène et sa vision du personnage de Mme de Stein.

C'est un souvenir qui date de 1991. C'était la première fois que Jean-Luc et moi travaillions sur un spectacle avec un seul personnage. Au début, c'était intimidant pour tous les deux d'avoir une seule personne en face de soi, lui dirigeant, moi sur le plateau essayant de suivre ses indications. On ne travaillait ensemble que les après-midis. On montait en bus à l'Espace-Planoise, puisque Jean-Luc ne conduisait pas et moi non plus. On avait la petite salle de l'Espace à nous tout seuls, lui sur un fauteuil, moi sur le plateau. C'était très curieux et, comme je l'ai dit tout à l'heure très intimidant, parce que Jean-Luc était quelqu'un que je connaissais depuis un certain temps mais pas comme metteur en scène me dirigeant. II avait toujours cet air de gamin avec ses fous rires que l'on ne comprenait pas toujours. J'avais dit quelque chose que je ne pensais pas être drôle et lui, ça le faisait rire.

C'est une pièce de Peter Hacks, traduite par Jean Jourdheuil ; la langue est très belle, très construite. Jean-Luc a fait des recherches sur la vie de Gœthe pour replacer l'épisode de Mme de Stein dans une chronologie historique. A partir de là, on a fait un spectacle structure, avec des gestes et des moments récurrents, ce que je n'imaginais pas du tout au départ. Cette pauvre Mme de Stein est au bord de la folie. Elle a eu une aventure avec Gœthe, une aventure imaginaire, et elle est restée avec ce souvenir. Parfois, elle avait des envolées lyriques accompagnées de grands gestes, puis elle reprenait plus simplement le fil de son discours. C'est Jean-Luc qui a apporté tout ça.

Quand je jouais, je voyais une femme enfermée dans ses principes. Elle avait été chargée par la Cour de Weimar d'inculquer à Gœthe les bonnes manières, de le policer car ce n'était qu'un rustre au départ. Mais cette femme pleine de principes avait des pulsions, des envies d'être différente, en tout cas de vivre ce qu'elle avait imaginé, ce qu'elle avait rêvé. On ne sait jamais si elle raconte la vérité : est-ce une illusion ou a-t-elle vraiment vécu quelque chose avec Gœthe ? Moi, je suis partie du principe qu'elle racontait la vérité pour pouvoir jouer. Mais pour le spectateur, il fallait laisser l'ambiguïté. On ne sait pas si Gœthe a réellement eu une passion pour 
elle. En fait, cela humilie Mme de Stein d'être amoureuse d'un rustre. La vision que j'en avais, c'est qu'elle était au bord d'un précipice, au bord de la folie.

Le costume a été choisi par Jean-Luc et Patricia Dubois, l'une des costumières du Théâtre de la Roulotte. Leurs discussions ont abouti à un costume faramineux, fait sur mesure à Paris. Il est constitué de tout une gamme de blancs et de crème et a été étudié jusqu'aux boutons de nacre; il est magnifique. Je le garde précieusement dans une malle. Je le prête parfois à des acteurs mais je ne l'ai jamais remis. C'est un beau costume parce que c'est le seul décor de la pièce. A côté, il y avait simplement des malles pour dire que Mme de Stein était peut-être en train de partir ou qu'elle se trouvait dans un grenier en train de rejouer son aventure.

\section{Liliane David et Jean-Luc Lagarce}

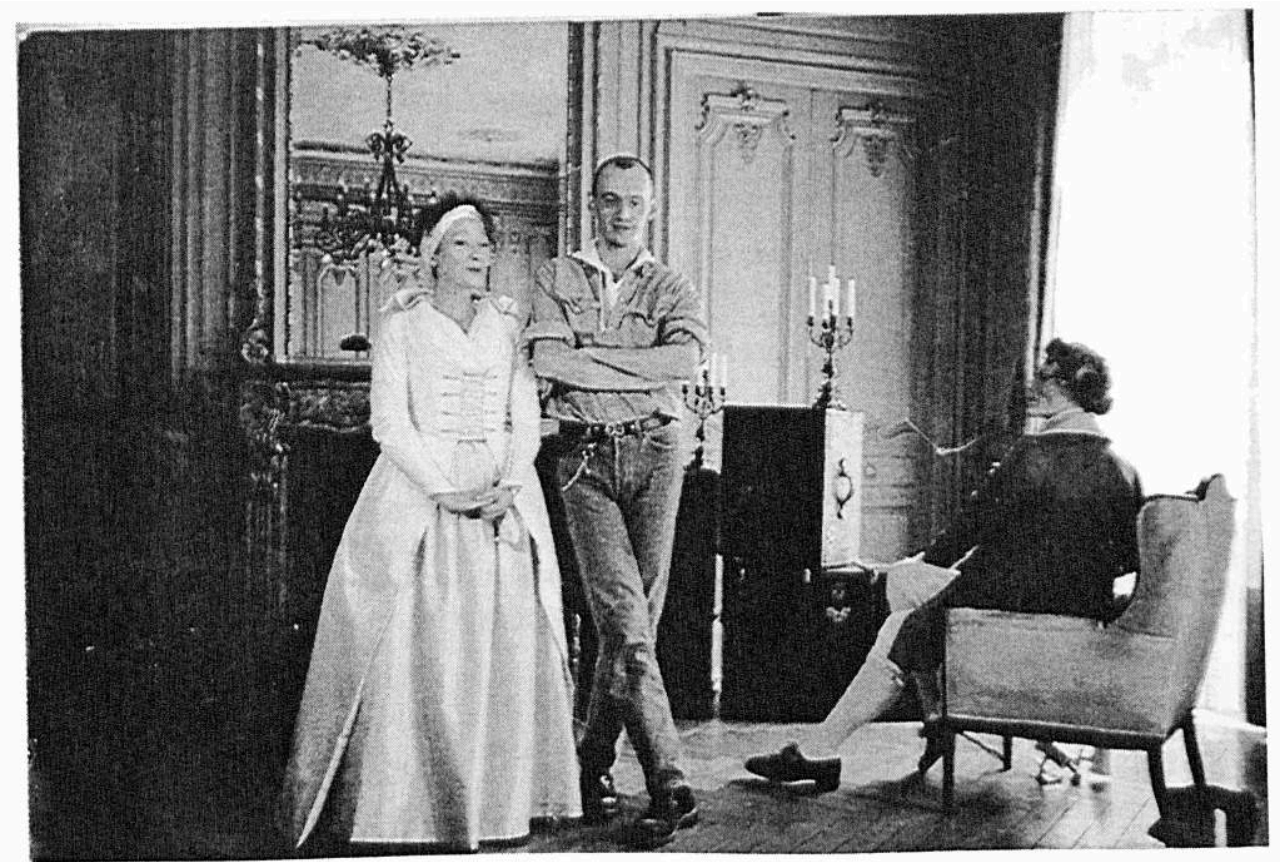

(Archives Liliane David) 